\title{
PENGARUH MOTIVASI DAN KEPEMIMPINAN TERHADAP KINERJA PEGAWAI PADA SEKRETARIAT DEWAN PERWAKILAN RAKYAT DAERAH KABUPATEN BREBES
}

\author{
Sri Ratih Handayani, Jaka Waskito, dan Gunistiyo \\ STIE Widya Manggalia Brebes dan Universitas Pancasakti Tegal
}

\begin{abstract}
The purpose of this study was 1) To determine the effect of motivation and on employee performance at the Regional Representative Council Secretariat in Brebes Regency 2) To determine the effect of leadership on employee performance at the Regional Representative Council Secretariat Brebes 3) To determine the effect of motivation and leadership together the same to the performance of employees in the Secretariat of the People's Representative Council of Brebes. respondent from this study were 55 people. Data sources used were questionnaire, observation, interview and literature study. This research method is descriptive research with a quantitative approach, namely the data used in the form of numbers that are analyzed using statistics. Oriented research is more focused on matters relating to the influence of motivation and leadership on employee performance. The research object revolves around factors motivational factors that influence employee performance include physiological aspects, appreciation, security and self-actualization and leadership and employee performance. From the results of data analysis conducted, it can be concluded that there is a positive relationship of motivation (X1) to employee performance (Y). It can be seen in the results of multiple regression tests obtained regression coefficient 0.265 (X1), which indicates that every one percent increase in motivation will cause an increase employee performance is equal to the coefficient value. And there is a positive relationship between leadership (X2) on employee performance $(Y)$ this can be seen in the results of multiple regression tests obtained regression coefficient 0.362 (X2), which shows that every one percent increase in leadership will cause an increase in employee performance at the coefficient value.
\end{abstract}

Keyword: motivation, leadership, performance

\section{A. PENDAhuluan}

Dengan adanya uraian di atas maka penulis tertarik untuk mengkaji permasalahan ini dalam bentuk penelitian dengan judul "Pengaruh Motivasi dan Kepemimpinan Terhadap Kinerja Pegawai pada Sekretariat Dewan Perwakilan Rakyat Daerah Kabupaten Brebes".

Dalam mencapai tujuan organisasi banyak unsur yang penting, salah satunya adalah unsur kepemimpinan.
Pimpinan perlu memikirkan usaha-usaha yang dapat dilakukan untuk memberi motivasi kepada para pegawai agar dapat bekerja dengan baik.

Manajemen merupakan hal yang umum dalam kehidupan manusia. Dalam manajemen terdapat perencanaan yang berkaitan dengan analisis, ramalan, dan identifikasi kebutuhan organisasi dari sisi sumber daya manusianya. Hal ini membantu mengidentifikasikan oleh organisasi di masa mendatang dan 
pengembangan yang diperlukan untuk mendapatkan orang-orang dengan kemampuan-kemampuan yang dibutuhkan.

Beberapa fenomena menunjukkan bahwa sumber daya manusia di negaranegara industri lebih siap dalam menyongsong masa depan. Negaranegara tersebut menjadi basis bagi pertumbuhan ekonomi negara-negara berkembang lain di kawasan Asia. Demikian juga untuk pendidikan angkatan kerja di negara negara industri lebih tinggi jika dibandingkan dengan negara-negara yang sedang berkembang. Maka dapat disimpulkan bahwa penguasaan teknologi dapat berjalan baik karena didukung oleh sumber daya manusia yang cakap.

Konsep pengembangan sumber daya manusia didasarkan kepada hubungan kesetaraan antar manusia yang dalam hal ini adalah tenaga kerja dengan sejumlah faktor produksi lain seperti tanah, material, dan mesin-mesin. Masing-masing faktor produksi mempunyai sumbangan yang berbeda-beda terhadap output total sesuai dengan mutu dan jenis faktor produksi tersebut. Manajemen menjadi semakin penting karena adanya peningkatan spesialisasi dalam kepegawaian dan juga adanya perkembangan skala operasi. Adanya kemajuan teknologi selalu menimbulkan berbagai macam tantangan.

Kemajuan teknologi yang tinggi tidak lepas dari peranan sumber daya manusia. Dengan demikian adanya kemajuan teknologi tidak berarti mengesampingkan tenaga manusia, karena maju atau tidaknya organisasi ditentukan oleh tenaga kerja manusia. Oleh karena itu kebutuhan dan keinginan pegawai harus diperhatikan secara intensif.

Pimpinan organisasi harus dapat memberikan keputusan yang efektif mengenai kesejahteraan pegawai berupa imbalan atau penghargaan sebagai bentuk motivasi. Jika motivasi yang diberikan kepada para pegawai sangat memadai, maka diharapkan prestasi kerja para pegawai akan meningkat. Pegawai akan bekerja dengan penuh semangat sehingga hasil kerja akan lebih memuaskan.

Kepemimpinan sangat mempengaruhi kehidupan organisasi. Kepemimpinan yang efektif dalam mengelola sumber daya manusia akan berpengaruh pada perilaku pegawai dan meningkatkan kinerja pegawai.Dengan demikian diduga ada pengaruh kepemimpinan terhadap kinerja pegawai. Kepemimpinan yang baik akan menyebabkan kinerja pegawai menjadi baik pula.

Motivasi sangat berpengaruh terhadap kinerja pegawai. Jika seseorang sudah merasa puas dengan pekerjaannya maka orang tersebut dikatakan mempunyai motivasi yang tinggi dan tanggung jawab serta disiplin kerja yang dapat menyebabkan pekerjaannya terselesaikan dengan baik. Kinerja pegawai harus selalu ditingkatkan karena kinerja yang baik akan membawa organisasi menuju ke arah yang lebih baik. Kinerja yang baik tidak terlepas dari

peran kepemimpinan seorang pimpinan organisasi. Organisasi yang efektif ditentukan oleh pola kepemimpinan yang efektif. Jika pimpinan dapat mengatur dan membimbing bawahan, memperhatikan kepentingan dan kesejahteraan bawahan dalam menjalankan pekerjaan maka pimpinan tersebut diteladani oleh para bawahan. Pimpinan dalam membuat kebijakan bersifat rasional sehingga dapat diterima oleh bawahan.

Seorang pimpinan mempunyai bekal kemampuan dan keterampilan sehingga dapat memimpin bawahan dengan baik. Keberhasilan organisasi sangat ditentukan oleh pola kepemimpinan organisasi. Tidak hanya itu, akan 
tetapi perilaku pegawai juga sangat menentukan keberhasilan organisasi.

Berdasarkan berbagai hasil temuan penelitian, pada kenyataannya masih terdapat kesenjangan hasil penelitian tentang pernyataan motivasi dan kepemimpinan yang berpengaruh terhadap kinerja. Ini disebabkan adanya perbedaan kepemimpinan pada Sekretariat Dewan Perwakilan Rakyat Daerah Kabupaten brebes. Maka dari itu memerlukan pengujian dan kajian kembali dalam model yang berbeda dengan penelitian lain khususnya dengan pendekatan hubungan variabel motivasi dan kepemimpinan yang mempengaruhi kinerja.

\section{B. TUJUAN PENELITIAN}

Tujuan yang ingin dicapai dari penelitian ini adalah:

1. Untuk mengetahui pengaruh motivasi danterhadap kinerja pegawai di Sekretariat Dewan Perwakilan Rakyat Daerah Kabupaten Brebes.

2. Untuk mengetahui pengaruh kepemimpinan terhadap kinerja pegawai di Sekretariat Dewan Perwakilan Rakyat Daerah Kabupaten Brebes.

3. Untuk mengetahui pengaruh motivasi dan kepemimpinan secara bersama-sama terhadap kinerja pegawai di Sekretariat Dewan Perwakilan Rakyat Kabupaten Brebes.

\section{TELAAH PUSTAKA}

\section{Motivasi}

Motivasi merupakan penyemangat bagi seseorang untuk menyelesaikan pekerjaan dengan baik yang mengandung kegiatan mengakibatkan, menyalurkan, dan memelihara perilaku manusia. Hal ini sangat penting bagi manajer dan pegawai dalam melaksanakan tugas. Pengaruh yang positif bagi mereka sangat dibutuhkan untuk meningkatkan hasil kerja.Dunia kerja tidak pernah terlepas dari masalah ini. Tanpa dorongan dan dukungan pegawai pekerjaan tidak akan terselesaikan dengan baik.

Menurut Fillmove H. Starford (A.A. Anwar Prabu Mangku negara, 1988:55) menyatakan "Motivasi sebagai suatu kondisi yang mengarahkan manusia ke arah suatu tujuan tertentu.

Motivating secara ekplisit dalam pengertian ini telah terlibat bahwa para pelaksana operatif dalam memberikan jasa-jasanya memerlukan beberapa macam perangsang. Motivasi merupakan langkah awal seseorang melakukan tindakan akibat adanya kekurangan secara fisik dan psikis atau dapat dikatakan sebagai suatu dorongan yang ditujukan untuk mencapai tujuan tertentu.

\section{Kepemimpinan}

Menurut (Kartini Kartono, 1994: 33) pemimpin adalah seorang pribadi yang memiliki kecakapan dan kelebihan khususnya kecakapan dan kelebihan suatu bidang, sehingga dia mampu mempengaruhi orang-orang lain untuk bersama-sama melakukan aktivitasaktivitas tertentu, demi pencapaian satu atau beberapa tujuan.

Kepemimpinan merupakan salah satu faktor yang mendorong organisasi untuk dapat mencapai tujuan organisasi. Perilaku pemimpin berorientasi kepada bawahan dan kepada hasil yang ingin dicapai.

\section{Kinerja}

Kinerja merupakan penilaian terhadap hasil kerja apakah sudah sesuai dengan apa yang direncanakan. Organisasi akan selalu mengevaluasi kinerja pegawai yang diadakan pada tiap periode waktu tertentu. Informasi tentang kinerja akan selalu diperlukan oleh organisasi untuk meningkatkan kemajuan organisasi. 
Kinerja adalah hasil yang dicapai dari yang telah dilakukan, dikerjakan seseorang dalam melaksanakan kerja atau tugas. Kinerja merupakan prestasi kerja atau performance, yaitu hasil kerja selama periode tertentu dibanding dengan berbagai kemungkinan.

Dalam hal ini kinerja bisa dikatakan hasil kerja secara kualitas dan kuantitas yang dicapai oleh seorang pegawai dalam melaksanakan tugasnya sesuai dengan tanggung jawab yang diberikan kepadanya.

Untuk mengetahui ukuran kinerja organisasi maka dilakukan penilaian kinerja. Penilaian kinerja adalah proses mengevaluasi seberapa baik pegawai melakukan pekerjaan mereka jika dibandingkan dengan standar dan kemudian mengkomunikasikan informasi tersebut kepada pegawai.

Kinerja pegawai merupakan hasil kerja secara kualitas dan kuantitas yang dicapai oleh seorang pegawai dalam melaksanakan tugasnya sesuai dengan tanggung jawab yang diberikan kepadanya.

Maka dalam penelitian ini penulis mengajukan hipotesis adalah sebagai berikut:

1. Motivasi berpengaruh signifikan terhadap kinerja pegawai pada Sekretariat Dewan Perwakilan Rakyat Daerah Kabupaten Brebes.

2. Kepemimpinan berpengaruh signifikan terhadap kinerja pegawai pada Sekretariat Dewan Perwakilan Rakyat Daerah Kabupaten Brebes.

3. Motivasi dan kepemimpinan secara bersama-sama berpengaruh signifi- kan terhadap kinerja pegawai pada

Sekretariat Dewan Perwakilan Rakyat Daerah Kabupaten Brebes.

\section{METODE PENELITIAN}

Penelitian ini adalah penelitian deskriptif dengan pendekatan kuantitatif, yaitu data-data yang digunakan berupa angka yang dianalisis dengan menggunakan statistik.Orientasi Penelitian ini lebih difokuskan pada hal-hal yang menyangkut tentang pengaruh motivasi dan kepemimpinan terhadap kinerja pegawai. Obyek penelitian ini berkisar kepada faktor-faktor motivasi yang memberikan pengaruh terhadap kinerja pegawai antara lain aspek fisiologis, penghargaan, rasa aman dan aktualisasi diri dan kepemimpinan serta kinerja pegawai.

\section{E. HASIL DAN PEMBAHASAN}

\section{Deskripsi Variabel penelitian}

Variabel penelitian dalam penelitian ini yaitu motivasi $\left(\mathrm{X}_{1}\right)$, semangat kerja $\left(\mathrm{X}_{2}\right)$, kepemimpinan $\left(\mathrm{X}_{3}\right)$ dan kinerja pegawai (Y) Sekretraiat DPRD Kabupaten Brebes. Dalam penelitian ini telah dilakukan pengukuran dengan kuesioner dan telah diperoleh data deskriptif sebagai berikut :

1. Motivasi $\left(\mathrm{X}_{1}\right)$

Variabel motivasi $\left(\mathrm{X}_{1}\right)$ diukur dengan 5 butir kuesioner dengan skor maksimal yang dapat diperoleh oleh seorang responden sebesar 25. Adapun paparan deskripsi hasil penelitian pada variabel motivasi $\left(\mathrm{X}_{1}\right)$ adalah sebagai berikut :

Tabel 6 : Deskripsi Motivasi $\left(\mathrm{X}_{1}\right)$

Descriptive Statistics

\begin{tabular}{|l|r|r|r|r|r|r|r|c|}
\hline & \multicolumn{1}{|c|}{$\mathrm{N}$} & Range & Minimum & Maximum & Sum & \multicolumn{2}{|c|}{ Mean } & Std. Deviation \\
\cline { 2 - 9 } & Statistic & Statistic & Statistic & Statistic & Statistic & Statistic & Std. Error & Statistic \\
\hline MOTIVASI & 55 & 12 & 13 & 25 & 1137 & 20.67 & .430 & 3.186 \\
Valid N (listwise) & 55 & & & & & & & \\
\hline
\end{tabular}

Sumber : Data primer diolah 
Dari tabel tersebut dapat diketahui bahwa skor terendah yang diperoleh responden adalah 13 dan skor tertinggi adalah 25 sedangkan skor rata-rata adalah 20,67 dengan nilai standar deviasi sebesar 3,186. Skor rata-rata tersebut dikonsultasikan dengan tabel predikasi untuk memperoleh predikat variabel motivasi $\left(\mathrm{X}_{1}\right)$.

Tabel 7 : Predikasi Motivasi $\left(\mathrm{X}_{1}\right)$

\begin{tabular}{|c|c|}
\hline Rentang Skor & Predikat \\
\hline $13,00-17,00$ & Rendah \\
\hline $17,01-21,00$ & Sedang \\
\hline $21,01-25,00$ & Tinggi \\
\hline
\end{tabular}

Sumber : Data Primer yang diolah dengan SPSS 16.0

Dari tabel tersebut dapat diketahui bahwa skor rata-rata motivasi $\left(\mathrm{X}_{1}\right)$ berada pada rentang 17,01 21,00. Dengan demikian variabel motivasi $\left(\mathrm{X}_{1}\right)$ berdasarkan pengukuran penelitian berpredikat sedang. Dapat disimpulkan bahwa kondisi tingkat motivasi dalam Sekretariat DPRD Kabupaten Brebes adalah sedang.
2. Kepemimpinan $\left(\mathrm{X}_{2}\right)$

Variabel kepemimpinan $\left(\mathrm{X}_{2}\right)$ diukur dengan 10 butir kuesioner dengan skor maksimal yang dapat diperoleh oleh seorang responden sebesar 42. Adapun paparan deskripsi hasil penelitian pada variabel kepemimpinan $\left(\mathrm{X}_{2}\right)$ adalah sebagai berikut :

Tabel 8 : Deskripsi Kepemimpinan $\left(\mathrm{X}_{2}\right)$

Descriptive Statistics

\begin{tabular}{|l|r|r|r|r|r|r|r|r|}
\hline & \multicolumn{1}{|c|}{$\mathrm{N}$} & \multicolumn{1}{c|}{ Range } & Minimum & Maximum & Sum & \multicolumn{2}{|c|}{ Mean } & Std. Deviation \\
\cline { 2 - 8 } & Statistic & Statistic & Statistic & Statistic & Statistic & Statistic & Std. Error & Statistic \\
\hline KEPEMIMPINAN & 55 & 13 & 29 & 42 & 2059 & 37.44 & .425 & 3.155 \\
Valid N (listwise) & 55 & & & & & & & \\
\hline
\end{tabular}

Sumber : Data primer diolah

Dari tabel tersebut dapat diketahui bahwa skor terendah yang diperoleh responden adalah 29 dan skor tertinggi adalah 42 sedangkan skor rata-rata adalah 37,44 dengan nilai standar deviasi sebesar 3,155 . Skor rata-rata tersebut dikonsultasikan dengan tabel predikasi untuk memperoleh predikat variabel kepemimpinan $\left(\mathrm{X}_{2}\right)$.

Tabel 9 : Predikasi Kepemimpinan $\left(\mathrm{X}_{2}\right)$

\begin{tabular}{|c|c|}
\hline Rentang Skor & Predikat \\
\hline $29,00-33,25$ & Rendah \\
\hline $33,26-37,50$ & Sedang \\
\hline $37,51-42,00$ & Tinggi \\
\hline
\end{tabular}

Sumber : Data Primer yang diolah dengan SPSS 16.0

Dari tabel tersebut dapat diketahui bahwa skor rata-rata kepemimpinan $\left(\mathrm{X}_{2}\right)$ berada pada rentang 37,51
- 42,00. Dengan demikian variabel kepemimpinan $\left(\mathrm{X}_{2}\right)$ berdasarkan pengukuran penelitian berpredikat 
tinggi. Dapat disimpulkan bahwa kondisi pada variabel kepemimpinan dalam Sekretariat DPRD Kabupaten Brebes adalah tinggi.

3. Kinerja Pegawai (Y)

Variabel kinerja pegawai (Y) diukur dengan 6 butir kuesioner dengan skor maksimal yang dapat diperoleh oleh seorang responden sebesar 28. Adapun paparan deskripsi hasil penelitian pada variabel kinerja pegawai $(\mathrm{Y})$ adalah sebagai berikut

Tabel 10 : Deskripsi Kinerja pegawai (Y)

Descriptive Statistics

\begin{tabular}{|l|r|r|r|r|r|r|r|r|}
\hline & \multicolumn{1}{|c|}{$\mathrm{N}$} & Range & Minimum & Maximum & Sum & \multicolumn{2}{|c|}{ Mean } & $\begin{array}{c}\text { Std. } \\
\text { Deviation }\end{array}$ \\
\cline { 2 - 9 } & Statistic & Statistic & Statistic & Statistic & Statistic & Statistic & Std. Error & Statistic \\
\hline KINERJA_PEGAWAI & 55 & 6 & 22 & 28 & 1384 & 25.16 & .214 & 1.584 \\
Valid N (listwise) & 55 & & & & & & & \\
\hline
\end{tabular}

Sumber : Data Primer diolah

Dari tabel tersebut dapat diketahui bahwa skor terendah yang diperoleh responden adalah 22 dan skor tertinggi adalah 28 sedangkan skor rata-rata adalah 25,16 dengan nilai standar deviasi sebesar 3,155.
Skor rata-rata tersebut dikonsultasikan dengan tabel predikasi untuk memperoleh predikat variabel kinerja pegawai sekeratriat DPRD Kabupaten Brebes (Y).

Tabel 11 : Predikasi Kinerja Pegawai (Y)

\begin{tabular}{|c|c|}
\hline Rentang Skor & Predikat \\
\hline $22,00-24,00$ & Rendah \\
\hline $24,01-26,00$ & Sedang \\
\hline $26,01-28,00$ & Tinggi \\
\hline
\end{tabular}

Sumber : Data Primer yang diolah dengan SPSS 16.0

Dari tabel tersebut dapat diketahui bahwa skor rata-rata kinerja pegawai (Y) berada pada rentang 244,01 - 26,00. Dengan demikian variabel kinerja pegawai (Y) berdasarkan pengukuran penelitian berpredikat sedang. Sehingga dapat disimpulkan bahwa kondisi pada tingkat kinerja pegawai dalam Sekretariat DPRD Kabupaten Brebes adalah sedang.

\section{Uji Validitas, Reliabilitas dan Colinearitas}

Analisis validitas dan relibilitas dilakukan untuk mengetahui seberapa tepat suatu alat ukur mampu melakukan fungsi. Alat ukur yang dapat digunakan dalam pengujian validitas suatu kuesioner adalah angka hasil kuesioner antara skor pernyataan dan skor keseluruhan pernyataan responden terhadap informasi dalam kuesioner.

Kriteria pengujian validitas dan reliabilitas adalah dengan membandingkan nilai korelasi validitas dan relibilitas dengan $r_{\text {tabel }}$ dengan menggunakan tingkat kepercayaan 95\% $(\alpha=$ 0.05) dan derajat kebebasan (df) $=\mathrm{n}-$ 2. Hasil pengujian validitas dan reliabilitas variabel motivasi $\left(\mathrm{X}_{1}\right)$ dapat dilihat pada tabel 12 berikut ini : 
Tabel 12 : Pengujian validitas dan reliabilitas variabel motivasi $\left(\mathrm{X}_{1}\right)$ :

\begin{tabular}{ccc}
\hline Nomor Pertanyaan & $\begin{array}{c}\text { R Product Moment } \\
(\mathbf{r x y})\end{array}$ & $\begin{array}{c}\mathbf{r} \text { tabel }(\alpha=\mathrm{n}-2) \\
\mathbf{5} \%=\mathbf{0 , 2 6 6}\end{array}$ \\
\hline & 0,910 & Valid \\
1 & 0,915 & Valid \\
2 & 0,870 & Valid \\
3 & 0,776 & Valid \\
4 & 0,731 & Valid \\
5 & Reliabel \\
\hline
\end{tabular}

Dari tabel tersebut, dapat diketahui bahwa hasil perhitungan validitas $r_{\text {hitung }}$ pada setiap pertanyaan variabel motivasi $\left(\mathrm{X}_{1}\right)$ mempunyai nilai lebih besar dari $\mathrm{r}_{\text {tabel. }}$. Demikian juga dengan perhitungan koefisien reliabilitas didapat $\mathrm{r}$ - alpha sebesar 0,890 lebih besar dari $r_{\text {tabel }}$ dengan menggunakan $\alpha=0,05$ didapat $\mathrm{r}_{\text {tabel }}$ sebesar 0,266. Dengan demikian dapat dikatakan bahwa pertanyaan yang tergabung dalam variabel motivasi $\left(\mathrm{X}_{1}\right)$ adalah valid dan reliabel untuk dijadikan instrumen penelitian.

Pengujian validitas dan reliabilitas variabel kepemimpinan $\left(\mathrm{X}_{3}\right)$ dapat dilihat tabel 13 berikut ini :

Tabel 13 : Pengujian validitas dan reliabilitas variabel kepemimpinan $\left(\mathrm{X}_{3}\right)$ :

\begin{tabular}{ccc}
\hline Nomor Pertanyaan & $\begin{array}{c}\text { R Product Moment } \\
(\mathbf{r x y})\end{array}$ & $\begin{array}{c}\mathbf{r} \text { tabel }(\alpha=\mathrm{n}-2) \\
\mathbf{5} \%=\mathbf{0 , 2 6 6}\end{array}$ \\
\hline & 0,286 & Valid \\
1 & 0,691 & Valid \\
2 & 0,536 & Valid \\
3 & 0,645 & Valid \\
4 & 0,551 & Valid \\
5 & 0,461 & Valid \\
6 & 0,536 & Valid \\
7 & 0,649 & Valid \\
8 & 0,461 & Valid \\
9 & 0,361 & Valid \\
10 & & Reliabel \\
\hline
\end{tabular}

Dari tabel tersebut, dapat diketahui bahwa hasil perhitungan validitas $r_{\text {hitung }}$ pada setiap pertanyaan variabel kepemimpinan $\left(\mathrm{X}_{2}\right)$ mempunyai nilai lebih besar dari $r_{\text {tabel. }}$. Demikian juga dengan perhitungan koefisien reliabilitas didapat $\mathrm{r}$ - alpha sebesar 0,431 lebih besar dari $\mathrm{r}_{\text {tabel }}$ dengan menggunakan $\alpha=0,05$ didapat $r_{\text {tabel }}$ sebesar 0,266. Dengan demikian dapat dikatakan bahwa pertanyaan yang tergabung dalam variabel kepemimpinan $\left(\mathrm{X}_{2}\right)$ adalah valid dan reliabel untuk dijadikan instrumen penelitian.

Sedangkan pengujian validitas dan reliabilitas variabel kinerja pegawai (Y) dapat dilihat pada tabel berikut ini : 
Tabel 14 : Pengujian validitas dan reliabilitas variable kinerja pegawai (Y)

\begin{tabular}{ccc}
\hline Nomor Pertanyaan & $\begin{array}{c}\text { R Product Moment } \\
(\mathbf{r x y})\end{array}$ & $\begin{array}{c}\mathbf{r} \text { tabel }(\alpha=\mathrm{n}-2) \\
\mathbf{5 \%}=\mathbf{0 , 2 6 6}\end{array}$ \\
\hline & & \\
1 & 0,365 & Valid \\
2 & 0,530 & Valid \\
3 & 0,395 & Valid \\
4 & 0,532 & Valid \\
5 & 0,398 & Valid \\
6 & 0,851 & Valid \\
\hline Nilai koefisien reliabilitas (r - alpha) $=0,446$ & Reliabel \\
\hline
\end{tabular}

Dari tabel tersebut, dapat diketahui bahwa hasil perhitungan validitas $r_{\text {hitung }}$ pada setiap pertanyaan variabel kinerja pegawai (Y) mempunyai nilai lebih besar dari $r_{\text {tabel. }}$. Demikian juga dengan perhitungan koefisien reliabilitas didapat $\mathrm{r}$ - alpha sebesar 0,446 lebih besar dari $\mathrm{r}_{\text {tabel }}$ dengan menggunakan $\alpha=0,05$ didapat $r_{\text {tabel }}$ sebesar 0,266. Dengan demikian dapat dikatakan bahwa pertanyaan yang tergabung dalam variabel kinerja pegawai (Y) adalah valid dan reliabel untuk dijadikan instrumen penelitian.

Sedangkan hasil uji kolinearitas pada variabel motivasi terhadap kinerja pegawai secretariat DPRD Kabupaten Brebes adalah sebagai berikut :

Tabel 15 : Hasil uji kolinearitas variabel motivasi dan kinerja pegawai

\begin{tabular}{|lll|r|r|r|r|r|}
\hline \multicolumn{1}{|c|}{ ANOVA Table } \\
\hline & & $\begin{array}{c}\text { Sum of } \\
\text { Squares }\end{array}$ & df & $\begin{array}{c}\text { Mean } \\
\text { Square }\end{array}$ & F & Sig. \\
\hline KINERJA_P & Between Groups & (Combined) & 60.277 & 9 & 6.697 & 4.005 & .001 \\
EGAWAI* & Linearity & 7.229 & 1 & 7.229 & 4.323 & .243 \\
MOTIVASI & Deviation & & & & & \\
& & from & 53.049 & 8 & 6.631 & 3.965 & .321 \\
& Linearity & & & & & \\
& & & 75.250 & 45 & 1.672 & & \\
\hline
\end{tabular}

Sumber : Data Primer Diolah

Dari tabel tersebut dapat dijelaskan bahwa hubungan antara kinerja pegawai dengan motivasi menghasilkan nilai $\mathrm{F}$ sebesar 3,965 sedangkan nilai signifikansi yang didapat adalah sebesar 0,321. Dari hal tersebut maka dapat disimpulkan bahwa pada kinerja pegawai dengan motivasi memiliki nilai $\mathrm{p}>0,05$ pada deviation from linearity sehingga dapat dibuktikan bahwa pada taraf kepercayaan 95 persen tidak terjadi penyimpangan signifikansi terhadap linearitas, sehingga dapat diartikan bahwa data tersebut memenuhi asumsi klasik kolinearitas sebagai prasyarat analisis regresi linear.

Hasil uji kolinearitas pada variabel kepemimpinan terhadap kinerja pegawai secretariat DPRD Kabupaten Brebes adalah sebagai berikut : 
Tabel 16 : Hasil uji kolinearitas variabel kepemimpinan dan kinerja pegawai

ANOVA Table

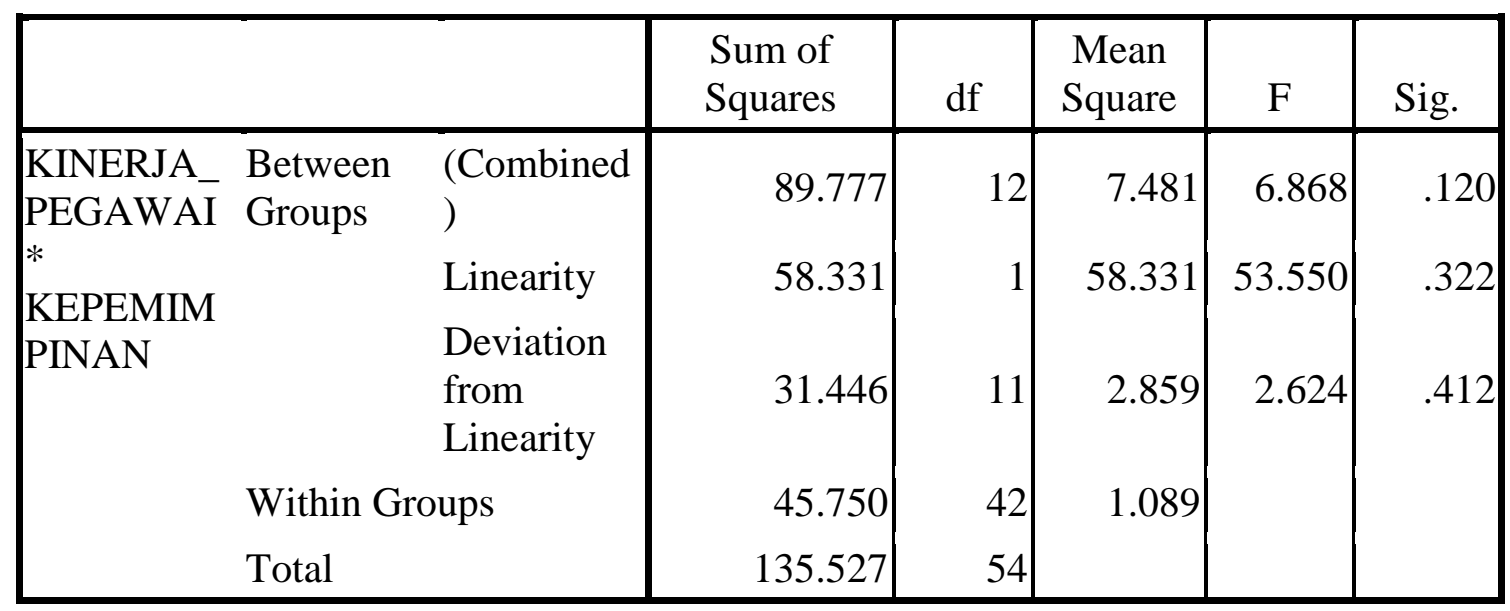

Sumber : Data Primer Diolah

Dari tabel tersebut dapat dijelaskan bahwa hubungan antara kinerja pegawai dengan motivasi menghasilkan nilai $\mathrm{F}$ sebesar 2,624 sedangkan nilai signifikansi yang didapat adalah sebesar 0,412 . Dari hal tersebut maka dapat disimpulkan bahwa pada kinerja pegawai dengan kepemimpinan memiliki nilai $\mathrm{p}>0,05$ pada deviation from linearity sehingga dapat dibuktikan bahwa pada taraf kepercayaan 95 persen tidak terjadi penyimpangan signifikansi terhadap linearitas, sehingga dapat diartikan bahwa data tersebut memenuhi asumsi klasik kolinearitas sebagai prasyarat analisis regresi linear.

\section{Analisis Regresi Berganda, Uji t Dan Uji F}

1. Analisis Regresi Berganda

Merupakan fungsi yang digunakan untuk mengetahui pengaruh motivasi, semangat kerja, kepemimpinan terhadap kinerja pegawai pada Sekretariat DPRD Kabupaten Brebes, maka digunakan alat analisis regresi berganda dengan rumus $\mathrm{Y}=\mathrm{a}+\mathrm{b}_{1}$ $\mathrm{X}_{1}+\mathrm{b}_{2} \mathrm{X}_{2}$.

Adapun hasil uji regresi berganda dapat dilihat pada tabel berikut ini :

Tabel 15 : Hasil Uji Regresi Berganda

Coefficients $^{\mathrm{a}}$

\begin{tabular}{|c|c|c|c|c|c|c|}
\hline \multirow{2}{*}{\multicolumn{2}{|c|}{ Model }} & \multicolumn{2}{|c|}{$\begin{array}{c}\text { Unstandardized } \\
\text { Coefficients }\end{array}$} & \multirow{2}{*}{$\begin{array}{c}\text { Standardized } \\
\text { Coefficients } \\
\text { Beta }\end{array}$} & \multirow[b]{2}{*}{$\mathrm{t}$} & \multirow[b]{2}{*}{ Sig. } \\
\hline & & $\mathrm{B}$ & Std. Error & & & \\
\hline 1 & (Constant) & 12.944 & 1.955 & & 6.622 & .000 \\
\hline & MOTIVASI & .265 & .059 & .130 & 3.090 & .000 \\
\hline & $\begin{array}{l}\text { KEPEMIMPIN } \\
\text { AN }\end{array}$ & .362 & .060 & .721 & 6.033 & .000 \\
\hline
\end{tabular}

a. Dependent Variable: KINERJA_PEGAWAI

Sumber : Data Primer Diolah 
Dari tabel tersebut di atas dapat dibuat persamaan $\mathrm{Y}=12,944+$ $0,265 X_{1}+0,362 X_{2}$

Dari hasil persamaan regresi tersebut dapat diinterpretasikan sebagai berikut:

- Nilai koefisien regresi 0,265 $\left(\mathrm{X}_{1}\right)$ pada variabel motivasi terdapat hubungan positif dengan kinerja pegawai. Hal ini menunjukkan bahwa setiap kenaikan satu persen dari motivasi akan menyebabkan kenaikan kinerja pegawai sebesar nilai koefisiennya.

- Nilai koefisien regresi 0,362 $\left(\mathrm{X}_{2}\right)$ pada variabel kepemimpinan terdapat hubungan positif dengan kinerja pegawai. Hal ini menunjukkan bahwa setiap kenaikan satu persen dari kepemimpinan akan menyebabkan kenaikan kinerja pegawai sebesar nilai koefisiennya.

- $\quad$ Nilai konstanta sebesar 12,944 mengartikan bahwa apabila kedua variabel bebas tersebut diabaikan, maka akan menyebabkan kinerja pegawai hanya sebesar koefisiennya.

2. Uji t tes

Pengujian secara parsial dengan menggunakan uji $\mathrm{t}$ bertujuan menentukan variabel mana dari variabel independen motivasi $\left(\mathrm{X}_{1}\right)$, dan kepemimpinan $\left(\mathrm{X}_{2}\right)$ yang memiliki pengaruh signifikan terhadap variabel dependen kinerja pegawai (Y).

Hasil perhitungan uji $t_{\text {hitung }}$ dilihat pada tabel berikut ini :

Tabel 16

Coefficients $^{\mathrm{a}}$

Hasil Uji $t_{\text {hitung }}$

\begin{tabular}{|c|c|c|c|c|c|c|}
\hline \multirow{2}{*}{\multicolumn{2}{|c|}{ Model }} & \multicolumn{2}{|c|}{$\begin{array}{l}\text { Unstandardized } \\
\text { Coefficients }\end{array}$} & \multirow{2}{*}{$\begin{array}{c}\begin{array}{c}\text { Standardized } \\
\text { Coefficients }\end{array} \\
\text { Beta }\end{array}$} & \multirow[b]{2}{*}{$\mathrm{t}$} & \multirow[b]{2}{*}{ Sig. } \\
\hline & & B & Std. Error & & & \\
\hline \multirow[t]{3}{*}{1} & (Constant) & 12.944 & 1.955 & & 6.622 & .000 \\
\hline & MOTIVASI & .265 & .059 & .130 & 3.090 & .000 \\
\hline & $\begin{array}{l}\text { KEPEMIMPIN } \\
\text { AN }\end{array}$ & .362 & .060 & .721 & 6.033 & .000 \\
\hline
\end{tabular}

a. Dependent Variable: KINERJA_PEGAWAI

Sumber : Data Primer diolah

Dari tabel tersebut dapat dijelaskan bahwa hasil perhitungan uji $t_{\text {hitung dengan menggunakan tingkat }}$ kepercayaan 95 persen dan derajat kebebasan (55-2) diperoleh $t_{\text {tabel }}$ sebesar 2,00575 dan hasil perhitungan pada SPSS pada variabel motivasi $\left(\mathrm{X}_{1}\right)$ menunjukkan 3,090. Hasil uji signifikansi menunjukkan bahwa $t_{\text {hitung }}>t_{\text {tabel }}$ yang mempunyai arti bahwa motivasi secara signifikan berpengaruh terhadap kinerja pegawai Sekretariat DPRD Kabupaten Brebes.

Perhitungan pada $\mathrm{X}_{2}$ didapat 6,033 yang mempunyai arti bahwa $t_{\text {hitung }}>t_{\text {tabel. }}$. Hal tersebut menunjukkan bahwa Ho ditolak atau kepemimpinan secara signifikan berpengaruh terhadap kinerja pegawai DPRD Kabupaten Brebes.

3. Uji F

Uji statistik $F$ pada dasarnya menunjukkan apakah semua variabel 
bebas yang dimasukkan dalam model mempunyai pengaruh secara bersama-sama atau simultan terhadap variabel terikat atau dependen (Imam Ghozali, 2006).

Berikut merupakan tabel hasil Uji F dengan menggunakan SPSS.

Tabel 17 : Hasil Uji F ( $\left.F_{\text {test }}\right)$

\begin{tabular}{|c|c|c|c|c|c|c|}
\hline \multicolumn{7}{|c|}{ ANOVA $^{b}$} \\
\hline \multicolumn{2}{|c|}{ Model } & $\begin{array}{l}\text { Sum of } \\
\text { Squares }\end{array}$ & $\mathrm{df}$ & Mean Square & $\mathrm{F}$ & Sig. \\
\hline 1 & Regression & 60.056 & 2 & 30.028 & 20.689 & $.000^{\mathrm{a}}$ \\
\hline & Residual & 75.471 & 52 & 1.451 & & \\
\hline & Total & 135.527 & 54 & & & \\
\hline
\end{tabular}

a. Predictors: (Constant), KEPEMIMPINAN, MOTIVASI

b. Dependent Variable: KINERJA_PEGAWAI

Sumber : Data Primer diolah

Dari hasil perhitungan tersebut dapat dijelaskan bahwa hasil Uji $\mathrm{F}$ yang dilakukan dengan menggunakan tingkat kepercayaan 95 persen $(\alpha$ $=0,05)$ dan $\mathrm{df}=\mathrm{n}-\mathrm{k}-1$ diperoleh $F_{\text {tabel }}$ sebesar 3,18. Sedangkan hasil perhitungan menunjukkan 20,689. Hal tersebut menunjukkan bahwa $\mathrm{F}_{\text {hitung }}>\mathrm{F}_{\text {tabel }}$ yang mengartikan hipotesis Ho ditolak yang mengartikan bahwa secara bersama-sama variabel bebas motivasi dan kepemimpinan terhadap kinerja pegawai berpengaruh terhadap variabel kinerja pegawai.

\section{Pembahasan}

1. Motivasi terhadap Kinerja pegawai Dari hasil analisis data yang dilakukan dapat disimpulkan bahwa terdapat hubungan positif motivasi $\left(\mathrm{X}_{1}\right)$ terhadap kinerja pegawai $(\mathrm{Y})$ hal ini terlihat pada hasil uji regresi berganda didapat koefisien regresi 0,265 $\left(\mathrm{X}_{1}\right)$, yang menunjukkan bahwa setiap kenaikan satu persen dari motivasi akan menyebabkan kenaikan kinerja pegawai sebesar nilai koefisiennya.
2. Kepemimpinan terhadap Kinerja Pegawai

Dari hasil analisis data yang dilakukan dapat disimpulkan bahwa terdapat hubungan positif antara kepemimpinan $\left(\mathrm{X}_{2}\right)$ terhadap kinerja pegawai (Y) hal ini terlihat pada hasil uji regresi berganda didapat koefisien regresi 0,362 $\left(\mathrm{X}_{2}\right)$, yang menunjukkan bahwa setiap kenaikan satu persen dari kepemimpinan akan menyebabkan kenaikan kinerja pegawai sebesar nilai koefisiennya.

Berdasarkan hasil perhitungan uji $\mathrm{t}$ didapat hasil perhitungan uji $\mathrm{t}_{\text {hitung }}$ dengan menggunakan tingkat kepercayaan 95 persen dan derajat kebebasan (55-2) diperoleh $t_{\text {tabel }}$ sebesar 2,00665 dan hasil perhitungan pada SPSS pada variabel motivasi $\left(\mathrm{X}_{1}\right)$ menunjukkan 3,090. Hasil uji signifikansi menunjukkan bahwa $t_{\text {hitung }}>t_{\text {tabel }}$ yang mempunyai arti bahwa motivasi secara signifikan berpengaruh terhadap kinerja pegawai Sekretariat DPRD Kabupaten Brebes.

Pada uji $t_{\text {hitung }}$ pada variabel kepemimpinan $\left(\mathrm{X}_{2}\right)$ dengan menggunakan tingkat kepercayaan 95 persen dan derajat kebebasan (55-2) diperoleh $t_{\text {tabel }}$ sebesar 2,00665 dan hasil perhitungan 
pada SPSS pada variabel kepemimpinan $\left(\mathrm{X}_{2}\right)$ menunjukkan 6,033 yang mempunyai arti bahwa $t_{\text {hitung }}>t_{\text {tabel. }}$ Hal tersebut menunjukkan bahwa Ho ditolak atau kepemimpinan secara signifikan berpengaruh terhadap kinerja pegawai Sekretariat DPRD Kabupaten Brebes.

Hasil perhitungan Uji $\mathrm{F}$ yang dilakukan dengan menggunakan tingkat kepercayaan 95 persen $(\alpha=0,05)$ dan $\mathrm{df}$ $=\mathrm{n}-\mathrm{k}-1$ diperoleh $\mathrm{F}_{\text {tabel }}$ sebesar 3,18. Sedangkan hasil perhitungan menunjukkan 20,0689. Hal tersebut menunjukkan bahwa $F_{\text {hitung }}>F_{\text {tabel }}$ yang mengartikan hipotesis Ho ditolak yang mengartikan bahwa secara bersama-sama variabel bebas motivasi dan kepemimpinan terhadap kinerja pegawai berpengaruh terhadap variabel kinerja pegawai.

\section{F. KESIMPULAN DAN SARAN}

\section{Kesimpulan}

Berdasarkan hasil penelitian dan pembahasan yang dilakukan yang telah diuraikan di atas, maka dapat ditarik kesimpulan sebagai berikut :

1. Motivasi kerja berpengaruh signifikan terhadap kinerja pegawai pada Sekretariat Dewan Perwakilan Rakyat Daerah Kabupaten Brebes. Sehingga hipotesis pertama yang menyatakan bahwa motivasi berpengaruh signifikan terhadap kinerja pegawai pada Sekretariat Dewan Perwakilan Rakyat Daerah Kabupaten Brebes adalah diterima.

2. Kepemimpinan berpengaruh signifikan terhadap kinerja pegawai pada Sekretariat Dewan PerwakilanRakyat Daerah Kabupaten Brebes. Sehingga hipotesis keduayang menyatakan bahwa kepemimpinan berpengaruh signifikan terhadap kinerja pegawai pada Sekretariat Dewan Perwakilan Rakyat Daerah Kabupaten Brebes adalah diterima.

3. Motivasikerjadankepemimpinan secara bersama-sama berpengaruh signifikan terhadap kinerja pegawai pada Sekretariat Dewan Perwakilan Rakyat Daerah Kabupaten Brebes. Sehinggadapatdiartikanbahwahipotes is keempat yang menyatakan bahwa motivasidan kepemimpinan secara bersama-sama berpengaruh signifikan terhadap kinerja pegawai pada Sekretariat Dewan Perwakilan Rakyat Daerah Kabupaten Brebes adalah diterima.

\section{Saran}

Berdasarkan kesimpulan di atas, maka penulis dapat memberikan saransaran sebagai berikut :

1. Pimpinan dapat memberikan hadiah tertentu bagi pegawai yang memiliki dedikasi dan prestasi yang baik, sehingga dapat memacu motivasi kerja pegawaiyang lain.

2. Pemberian motivasi kerja yang dilakukan pimpinan bukan hanya masalah apa yang akan diberikan oleh pimpinan tapi dapat juga dengan melakukan pendekatan-pendekatan secara persuasif antara pimpinan dengan anak buahnya, sehingga tidak ada jarak yang terlalu jauh antara pimpinan dengan anak buah.

3. Pimpinan dapat memberikan teguran dan atau bila perlu dengan sangsi kepada pegawai yang tidak melaksanakan pekerjaannya dengan baik.

\section{DAFTAR PUSTAKA}

Alfan, Luthfi. 2016. Pengaruh Gaya Kepemimpinan Dan Motivasi Kerja Terhadap Kinerja Pegawai Pada Kantor Lingkungan Hidup Di Kabupaten Brebes. Hal. 10. 
Arikunto, Suharsimi. 2010. Dasar-Dasar Evaluasi Pendidikan. Jakarta : Rineka Cipta.

Ardana I Komang 2012, Manajemen Sumber Daya Manusia, Jakarta : Graha Ilmu.

Dharmawan, I Made Yusa. 2011. Pengaruh Kompensasi Dan Lingkungan Kerja non Fisik Terhadap Disiplin Dan Kinerja Karyawan Hotel Nikki Denpasar. Online.www.pps.unud.ac.id

Demokrat, Satria Negara, 2011. Pengaruh Kompensasi Terhadap Kinerja Dengan Motivasi Kerja Sebagai Variabel Moderating. Online.www.core.ac.uk

Hamalik Oemar, 2006, Pengembangan Sumber Daya Manusia Manajemen Pelatihan Ketenagakerjaan Pendekatan Terpadu, Jakarta : BumiAksara

Herdiandito, Anoki, 2010. Pengaruh Kompensasi Terhadap Kinerja Karyawan PT. Slamet Langgeng Purbalingga Dengan Motivasi Kerja sebagai Variabel Intervening. Online.www.core.ac.uk

Istianto, 2009, Riset Sumber Daya Manusia, Cara Praktis Mendeteksi DimensiDimensi Kerja Karyawan, Jakarta : PT. Gramedia

Juniantara, 2015. Pengaruh Motivasi Dan Kepuasan Kerja Terhadap Kinerja Karyawan Koperasi Di Denpasar. Online

Keran, Kristina Nugi, 2012. Pengaruh Motivasi Kerja Kompetensi Dan Kompensasi Terhadap Kinerja Karyawan Di Yayasan Bintang Timur Tangerang. Online.www.digilib.esaunggul.ac.id

Kurniadi, Fajar, 2012. Pengaruh Kompensasi Dan Motivasi Terhadap Kinerja Karyawan Di Apotek Berkah. Online.www.sepoditory.widyatama.co.i

Mangkunegara, Anwar Prabu, 2010, Sumber Daya Manusia, Bandung: Remaja Rosdakarya.

Moekijat, 2010. Manajemen Sumber Daya Manusia. Mandar Maju : Bandung,

Nurhayati, Lita. 2016. Pengaruh Motivasi Dan Semangat Kerja Terhadap Kinerja Pegawai Pada Rumah Sakit Umum Daerah Kabupaten Brebes.

Randupandojo, Heidjrahmandan Suad Husnan, 2004, Manajemen Personalia, Yogyakarta : BPFE

Siagian, Sondang P, 2008, Teoridan Praktek Kepemimpinan, Jakarta : Rineka Cipta

Singarimbun, M., dan Sofyan Effendi, 1989, Metode Penelitian Survei, Edisi Revisi, Jakarta : PT. Pustaka LP3ES

Sugiyono, 2009. Statistika Untuk Penelitian. Tarsito: Bandung

Suwanti, 2011. Pengaruh Motivasi Dan Kepemimpinan Terhadap Kepuasan Kerja Pegawai Pada Dinas Kesehatan Kabupaten Brebes. Hal. 20.

Teguh Sulistiyani, Teguh, Rosidah, 2003, Manajemen Sumber Daya Manusia. Yogyakarta : Graha Ilmu 